\title{
Claire Fauvergue, Diderot, lecteur et interprète de Leibniz
}

\section{Paola Perazzolo}

\section{Q OpenEdition}

1 Journals

\section{Edizione digitale}

URL: http://journals.openedition.org/studifrancesi/9563

DOI: $10.4000 /$ studifrancesi.9563

ISSN: 2421-5856

\section{Editore}

Rosenberg \& Sellier

\section{Edizione cartacea}

Data di pubblicazione: 1 décembre 2007

Paginazione: 665-666

ISSN: 0039-2944

\section{Notizia bibliografica digitale}

Paola Perazzolo, «Claire Fauvergue, Diderot, lecteur et interprète de Leibniz», Studi Francesi [Online], 153 (LI | III) | 2007, online dal 30 novembre 2015, consultato il 10 janvier 2021. URL: http:// journals.openedition.org/studifrancesi/9563 ; DOI: https://doi.org/10.4000/studifrancesi.9563

Questo documento è stato generato automaticamente il 10 janvier 2021.

\section{(c) (i) (9)}

Studi Francesi è distribuita con Licenza Creative Commons Attribuzione - Non commerciale - Non opere derivate 4.0 Internazionale. 


\title{
Claire Fauvergue, Diderot, lecteur et interprète de Leibniz
}

\author{
Paola Perazzolo
}

\section{NOTIZIA}

CLAIRE FAUVERGUE, Diderot, lecteur et interprète de Leibniz, Paris, Champion, 2006 («Les DixHuitièmes siècles», 98), pp. 278.

1 Nel presente volume l'autrice esplora i rapporti e le filiazioni esistenti tra la filosofia di due pensatori apparentemente diversissimi tra loro, Leibniz e Diderot. Non di influenza di tratta - per il co-direttore dell'Encyclopédie il filosofo è eclettico, pensa da solo ed esercita in questo modo la sua libertà -, ma di quella che viene definita da Fauvergue come una «convergence métathéorique»: Diderot rilegge così un filosofo non materialista di cui riutilizza i concetti senza accettarne la metafisica. Tale convergenza permette di ritrovare svariate continuità tra i due autori. Nell'articolo «Syncrétistes» dell'Encyclopédie Diderot sostiene che non è tanto importante accordare un sistema con un altro, quanto vedere se è conforme all'esperienza. Perciò, idee astratte della metafisica quali il concetto dell'armonia prestabilita o della perfezione possono costituire il germe di nuove verità se si scopre a che realtà fenomenale rinviano. C. Fauvergue verifica questa convergenza metateorica da prospettive e approcci differenti, esaminando dapprima le affinità concettuali tra i due pensatori per mostrare come Diderot richiami e reinterpreti in chiave materialista alcuni grandi principi della filosofia leibniziana - il principio degli indiscernibili, il concetto di inquietudine o quello di monade, la legge della continuità -, e passando poi a un approccio più testuale. L'autrice esamina in particolare l'articolo dell'Encyclopédie «Leibnitzianisme ou Philosophie de Leibniz», la cui seconda parte - che costituisce l'esposizione abbreviata della filosofia del pensatore tedesco - non si limita a fornire un riassunto di seconda mano, ma propone invece la traduzione di un testo latino intitolato Méditations sur la connaissance, la vérité et les idées e di una versione latina della Monadologie. Quest'articolo rivela Diderot come un grande "traduttore" di filosofia, mostrandone la conoscenza di 
Leibniz e confermando la convergenza metateorica tra metafisica e materialismo riscontrata da Fauvergue, che termina il suo lavoro analizzando l'ulteriore eredità del filosofo tedesco nel pensiero diderotiano. Per l'autrice, tale lascito appare evidente in più testi, quali ad esempio le Lettres sur les aveugles o le Lettres sur les sourds et les muets: non solo il progetto di anatomia metafisica deriverebbe dalla teoria delle piccole percezioni di Leibniz, ma anche l'idea di inquietudine sarebbe comune a entrambi i pensatori, a dimostrazione del fatto che è possibile riutilizzare gli strumenti concettuali di un autore senza adottarne la metafisica. 